\title{
Seat Belt Injuries of the Lumbar Spine-Stable or Unstable?
}

W. Y. Yu, MB, BS(hons), MSc, FRCS(C), C. M. Siu, MB, BS, FRCP(C) Spinal Cord Injury Unit, University Hospital, University of British Columbia, Vancouver, Canada

\section{Summary}

Twenty six patients with seat belt injuries of the lumbar spine were admitted into the Spinal Cord Injury Unit of the University Hospital, University of British Columbia, in the past 10 years. Four patients with pure ligamentous injuries were primarily treated surgically. Sixteen patients were treated with closed methods with a Stryker frame followed by a body cast or brace. Significant angulation with spinal deformity occurred in 6 patients. The common factor of failure of closed treatment was the inadequate reduction of initial angulation. When the initial angulation at the fracture site was adequately reduced, closed methods were associated with satisfactory results with no serious disability seen in long term follow-up. Open reduction with fixation with compression rods or wiring and fusion invariably leads to good results. It is recommended that patients with seat belt fractures of the lumbar spine may be treated by a closed method provided good reduction is obtained initially, otherwise open reduction and posterior fusion is more preferable.

Key words: Seat belt injuries; Lumbar spine; Unstable fracture; Stable fracture; Spine fracture management.

In 1948 Chance first described a horizontal splitting of the vertebra and vertebral arch which ended in an upward curve (Chance, 1948) (Fig. 1). The mechanism of injury was believed to be forward flexion. Since 1969, several authors (Smith, 1969; Rogers, 1971; Williams, 1971; Huelke, 1975; Hubbard, 1976) noticed the relationship between the use of seat belts and a flexion distraction type of fracture with features similar to those described by Chance. Denis (1985) classified seat belt fractures into four types (Fig. 2). The first type is a pure ligamentous disruption with facet dislocation; the second type is the classical Chance fracture with horizontal splitting of bone; the third type is a twolevel injury through the posterior ligamentous complex, pedicle and disc and the fourth type is a two-level injury through the posterior ligamentous complex, pedicle, body and disc. Whereas there is general agreement that pure ligament- 


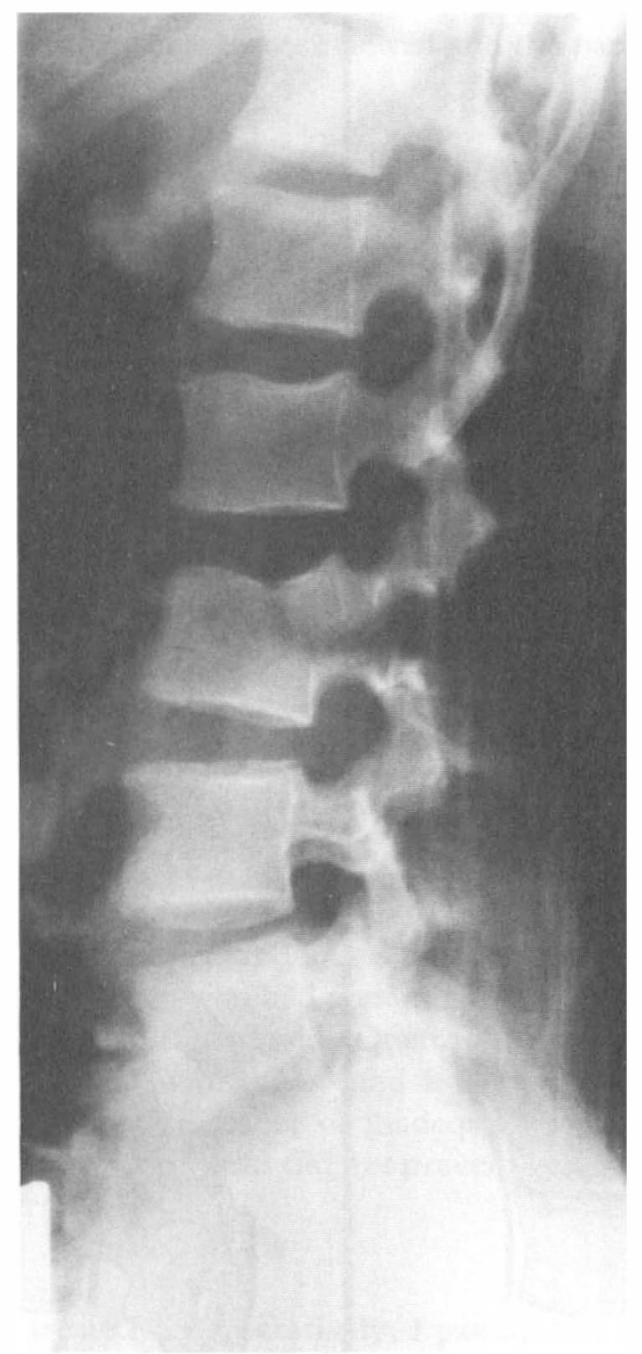

Figure 1 Lateral view of lumbar spine of Chance fracture with horizontal split of spinous process and neural arch.

ous injury with a facet dislocation type of seat belt fracture is unstable, there is less agreement regarding the stability of the other types of seat belt injuries.

The purpose of this study is to review our experience and results of management of seat belt injuries of the lumbar spine in our hospital and in particular, to address the issue of the stability of the other three types of seat belt injuries of the lumbar spine.

\section{Materials and methods}

Between July 1978 and June 1988, there were twenty six patients with seat belt type injuries admitted into the Acute Spinal Cord Injury Unit of the University Hospital. The criteria for diagnosis were: 


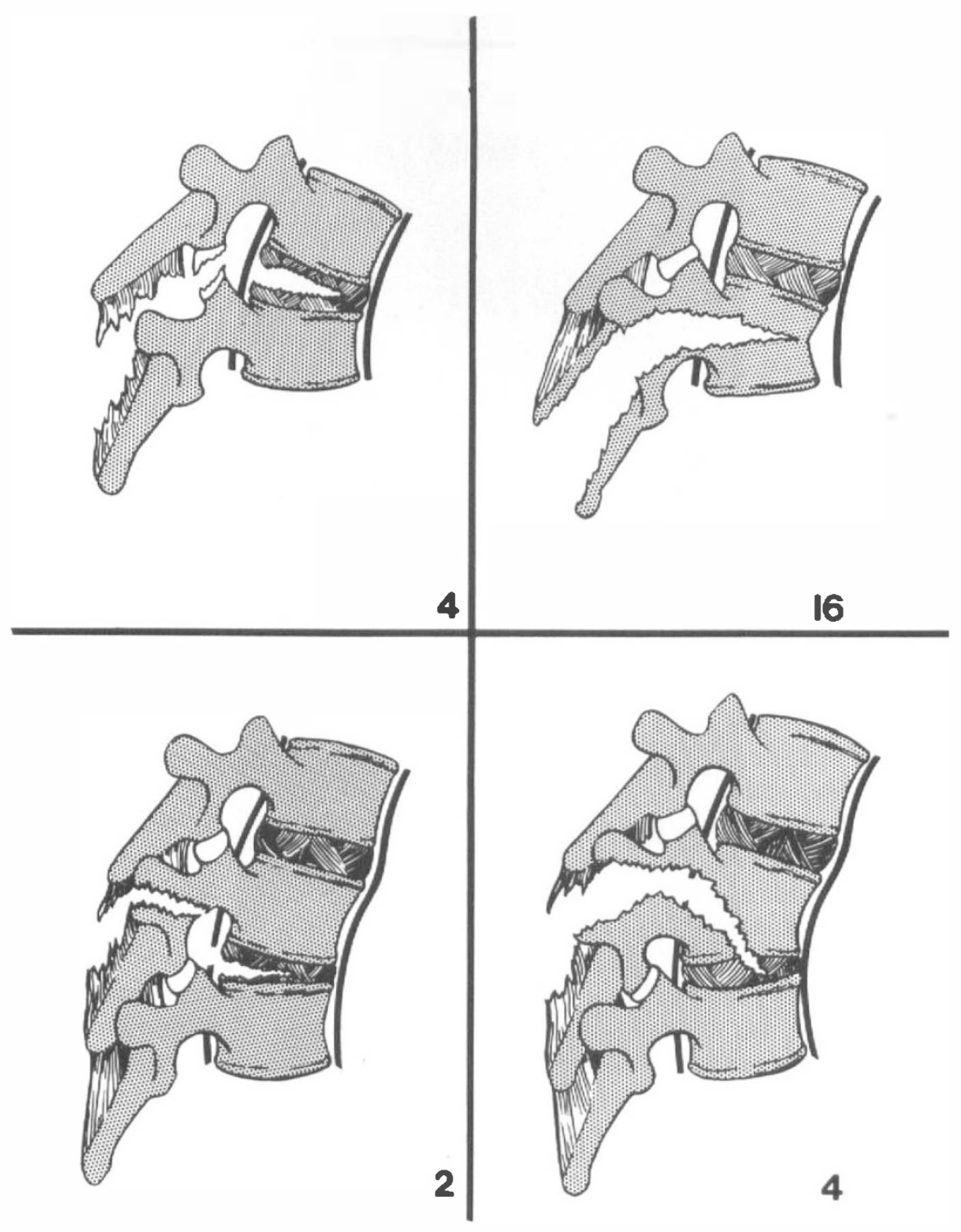

Figure 226 patients with flexion distraction injuries to lumbar spine, 4 patients with pure ligamentous injury with facet dislocations were excluded, of the remaining 22 patients with Chance type of fracture, 16 were one-level injuries and 6 were two-level injuries.

1. Presence of lumbar vertebra injury.

2. Injury sustained in an MVA with use of seat belt.

3. Presence of bruising and ecchymosis along the site of application of the seat belt.

Four patients had a pure ligamentous injury with facet dislocations and were surgically treated due to recognised instability and were excluded from this study. Of the 22 patients, 16 were type 2, 2 were type 3 and 4 were type 4 (Fig. 2 ). 
The charts and radiographs were reviewed and the patients were followed up clinically.

\section{Results}

There were 14 females and 8 males. The average age was $25 \cdot 2$ years (range $16-$ 48). Of the 22 patients, 20 were wearing lap belts and 2 used three-point restraint belts. There were 12 single vehicle accidents, 4 head-on collisions, 2 side swipes and 2 front side hits, and in 2 patients the type of accident was not recorded.

Of the 22 patients, 17 had no neurological deficit, 3 had a mild deficit (2 nerve roots or less), 1 had a severe cauda equina injury, and 1 had complete cord lesion due to rupture of the cord at T7 level.

The levels of fractures were L1 (5), L2 (8), L3 (7) and L4 (2).

Associated injuries were frequent. There were 4 patients with blunt abdominal trauma, 3 with bowel rupture and 1 with traumatic pancreatitis. There was renal contusion in 5 patients with haematuria, 3 patients had a head injury and 1 patient a faciomaxillary injury, 4 patients had injury to the chest and 8 patients had long bone fracture, 1 patient had hypothermia.

\section{Treatment}

Sixteen patients (12 with type 2, 1 type 3, 3 type 4) were treated non-surgically with a Stryker Frame. Postural reduction followed by hyperextension cast was carried out in all but 2 cases who had abdominal injuries with ongoing sepsis in whom reduction was not attempted. Open reduction was carried out in 6 patients ( 2 with type 2, 1 with type 3 and 1 with type 4 injury), 4 were done primarily and 2 were done because of inadequate closed reduction. Delay of surgical treatment of up to 6 weeks did not prevent good reduction.

\section{Results}

Of the 16 patients treated non-operatively, 1 patient had non-union. This was a patient with a type two fracture. Significant angulation occurred in 6 patients of which 3 patients had angulation of more than 30 degrees (Fig. 3), and 3 patients had angulation between 20 to 30 degrees. Tendency to angular occurred in all 3 types. No significant angulation occurred in 9 patients, (Fig. 4). The majority of patients with angulation occurred in fractures of L1 to L3. At the time of follow-up, 13 patients had no significant back pain, 2 patients with angulation of 30 degrees or more had infrequent backache. The average followup was 4 to 6 years (range 1.6 to 9 years). One patient went onto non-union with serious angulation because reduction and immobilisation were not attempted due to prolonged serious abdominal sepsis.

All 6 patients treated with open reduction and fixation with Harrington Compression Rods (3) and wiring and fusion (3) had good results with anatomical reduction and solid fusion (Fig. 5). At the time of follow-up, average 2.6 years (range 8 months to $3 \cdot 2$ years), all were pain free. Neurological recovery of nerve roots and cauda equina occurred in all of the 4 patients, irrespective of the method of treatment. 


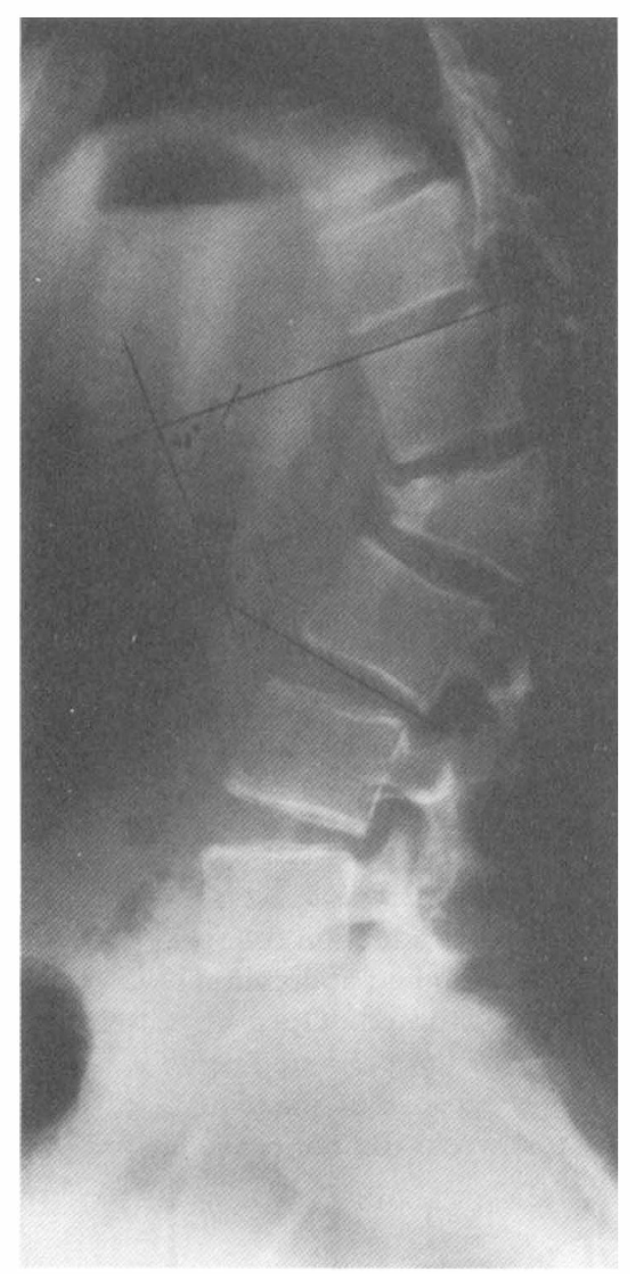

Figure 3 Chance fracture healed with significant deformity.

\section{Discussion}

The stability of spinal fracture is a subject of controversy.

It is generally accepted that an unstable fracture is one with movement at the fracture site, likely to be associated with neural deficit, and heals with deformity. If the above criteria are used to judge instability, then the seat belt fracture is not a totally stable fracture as it may heal with deformity. When we reviewed all the cases with significant angulation at the fracture site, it was obvious that either the initial angulation was not adequately reduced, or not adequately maintained in a hyperextension cast. All those patients with their initial angulation reduced and maintained healed well with no deformity.

The seat belt fracture, with distraction of the middle and posterior columns, and an intact anterior column is stable. However, if the anterior column is also involved, the seat belt fracture is unstable in the unreduced position due to laxity of the anterior longitudinal ligaments, but stable when reduced, as the 


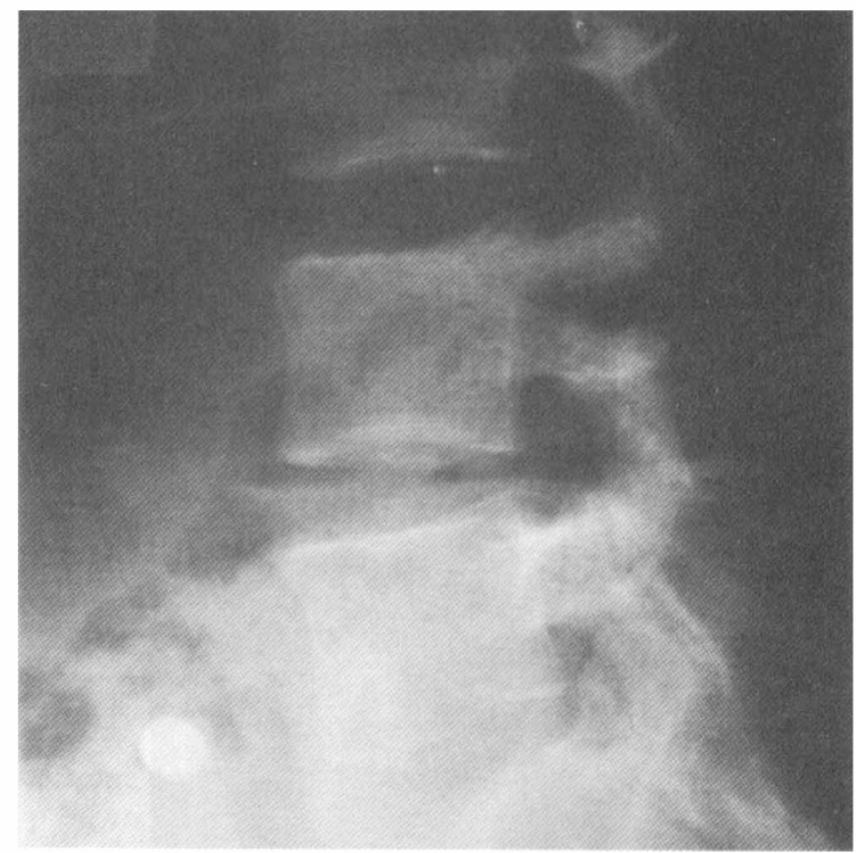

Figure 4 Chance fracture healed with no significant deformity.

anterior longitudinal ligament is right in the reduced position and acts as a hinge.

Even though, at the time of follow-up, those patients with their fractures healed with angulation had no serious pain, the loss of normal lordosis of the lumbar spine was undesirable and potentially may give rise to significant mechanical low back pain. It is therefore, recommended that if initial reduction of a seat belt fracture is not satisfactory, or reduction is not maintained, open reduction with posterior fixation and fusion is indicated.

\section{Conclusions}

1. Seat belt fracture of lumbar spine may be treated non-operatively if good reduction is obtained and maintained.

2. Significant progressive angulation at the fracture site may occur if the initial angulation is not reduced.

3. Open reduction with posterior stabilisation and fusion invariably gives rise to good results.

\section{References}

Chance GQ 1948 Not on a type of flexion fracture of the spine. British fournal of Radiology 21:452-453.

DEHNER JR 1971 Seatbelt injuries of the spine and abdomen. AfR 111:833-843.

DENIS F, ARMSTRONG GWD, LIVERMORE N 1985 A morphological classification of thoracolumbar injuries. Fournal of Bone and foint Surgery 67B:99. 


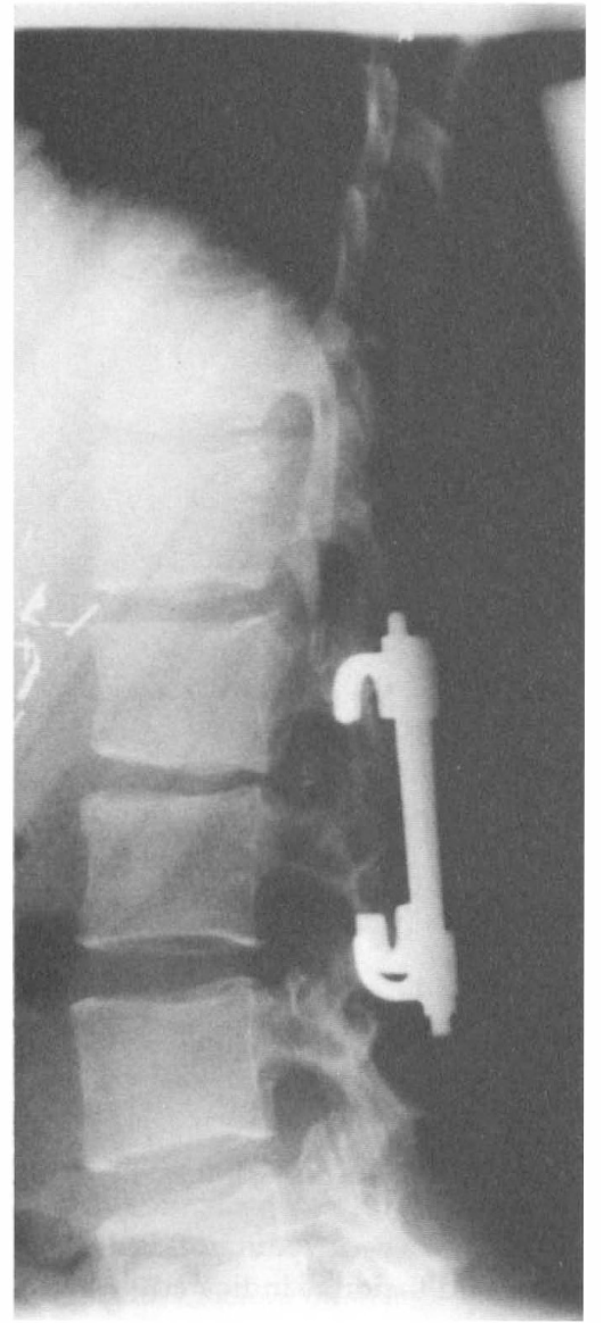

Figure 5 Open reduction posterior stabilisation with compression Harrington rods resulted in good result.

HubBaRd DD 1976 Fracture of the dorsal and lumbar spine. Orthopedic Clinics of North America 7:606-614.

HUELKE DF, KAUfER H 1975 Vertebral column injuries and seat belts. Fournal of Trauma 15:304-318.

KELLY RP, WhITESIDES TE 1968 Treatment of Lumbodorsal Fracture Dislocations. Annals of Surgery 167:705-717.

ROGERS LF 1971 The roentgenographic appearance of transverse or chance fractures of the spine. The seat belt fracture. $A \mathscr{f} R$ 111:844-849.

SMITH WS, KAUFER H 1969 Patterns and mechanisms of lumbar injuries associated with lap seat belts. Fournal of Bone and foint Surgery 51A92:239-254.

Williams JS, KIRKPATRICK JR 1971 Nature of seat belt injuries. Fournal of Trauma 11:207-217. 